\title{
Los planes provinciales de obras y servicios
}

\author{
por \\ JOSE LUIS GONZALEZ BERENGUER \\ Doctor en Derecho y en Ciencias Políticas \\ Secretario de 1. ${ }^{\text {a }}$ Categoria de Administración Local
}

1 La insuficiencia de las Haciendas municipales, especialmente las de los Ayuntamientos pequeños, es un mal endémico al que el Estado ha intentado poner remedio repetidamente, siendo los fracasos tan numerosos como los intentos. El grave error de un tratamiento legal unitario para toda clase de Ayuntamientos, sea cualquiera su volumen y capacidad económica, ignorando la realidad de una falta total de soberanía fiscal en los pequeños $y$, por otra parte, la alta probabilidad de que aunque el error se corrigiera, jamás podrían los Municipios inferiores a las dos decenas de millares de habitantes conseguir sanear su hacienda, han llevado al Poder central a arbitrar sistemas de auxilios tendentes a suplir aquellas deficiencias. Además de ello, e independientemente, el costo verdaderamente prohibitivo de ciertas obras, obligatorias para los Municipios de más de cinco mil almas, imposibilita a sus Ayuntamientos para intentar siquiera el emprenderlas con sus propios medios. Los sistemas de auxilios a que se ha aludido, se han concretado en las normas siguientes: 
A) El sistema anterior a la Ley de Régimen local.

Muy a grosso modo relacionaremos algunas de las leyes de auxilios, hasta la Ley de Régimen local. Todas tienen un común denominador: la ayuda corre a cargo de organismos de la Administración central y se dirige a financiar obra's y sercios determinados, afines con el organismo subvencionante.

1. Abastecimiento de aguas. Para Municipios inferiores a 12.000 habitantes: Decretos del Ministerio de Obras Públicas de 17 de mayo de 1940 ("B. O." del 12 de julio), 17 de marzo de 1950 ("B. O." del 21 de marzo), Orden ministerial de 30 de agosto de 1940 ("B. O.) del 1 de septiembre), Decreto de 1 de febrero de 1952 ( (B. O.) del 10 de febrero). Para Municipios de $\mathbf{1 2 . 0 0 0}$ a $\mathbf{5 0 . 0 0 0}$ habitantes: Decreto del Ministerio de Obras Públicas de 27 de julio de 1944 (wB. O." 'de 10 de agosto) y 1 de febrero de 1952 y 5 de octubre de 1953.

2. Alumbramiento de arguas: Real Decreto de 28 de junio de 1910, Decreto de 23 de agosto de 1934 ("Gaceta" del 29), 20 de diciembre de 1934 ("Gaceta" del 22), Orden ministerial de 15 de octubre de 1.934 ("Gaceta" del 18), y Decreto de 23 de octubre de 1941 ("B. O.) del 25).

3. Caminos rurales. Ley de 29 de junio de 1911 ("Gaceta" del 5 de julio), Reglamento de 23 de julio de 1924 ("Gaceta" del 28).

4. Colonización y repoblación interior: Ley de 27 de abril de 1946 ("'B. O." del 28), Reglamento de 10 de enero de 1947 ("B. O." del 7 de febrero).

5. Escuelas: Decreto de 15 de julio de 1934 ("Gaceta" del 17), Decreto de 18 de febrero de 1936 , Decreto de 29 de abril de 1949 ("B. O." del 12 de mayo).

6. Repoblación forestal: Ley de auxilios de $\mathbf{1 9 4 7 .}$

7. Viviendas: Ley de 19 de abril de 1939 , Ley de 24 de noviembre de 1939, Ley de 27 de julio de 1951 ; Decreto Ley da 10 de agosto de 195.) : Orden ministerial de 11 de febrero de 1957 ; 
Decreto de 5 de abril de 1957; Decreto de 22 de noviembre de 1957 ; Decreto de 24 de enero de 1958 ; Orden de 1 de febrero de 1958, etcétera.

B) El sistema de la Ley de Régimen local y su Reglamento DE SERvicios

1. Ley de Régimen local de $\mathbf{1 9 5 0 .}$

Dice ésta, en su artículo 255: "La Provincia cooperará a la efectividad de los servicios municipales, principalmente de los obligatorios que no puedan ser establecidos por los Ayuntamientos, y recibirá para ello del Estado la ayuda financiera a que aluden los artículos siguientes». El articulo siguiente fi.ja para los Ayuntamientos la obligación de contribuir "a los gastos de establecimiento con la cantidad que corresponda a la capacidad de crédito (cuya estimación contiene el artículo 257) de cada una de las Entidades municipales interesadas"). Respecto a la ayuda del Estado a las Diputaciones para la cooperación, el' artículo 258 la limita a la construcción de caminos "mientras se considere necesarion.

2. El texto refundido de la Ley de Régimen local establece un orden de preferencia en las obras y servicios a costear; que es el siguiente: abastecimiento de aguas, abrevaderos y lavaderos; alcantarillados, alumbrado, botiquín, baños públicos, matadero, mercado, extinción de incendios, campos escolares de deportes, cementerios y los demás comprendidos en los artículos 101 y 103 de la Ley ide Régimen local (artículo 255). El número 6 del propio artículo, establece como formas de cooperación la orientación económica, las subvenciones y anticipos, la ejecución de obras e instalación de servicios, la creación de instituciones de crédito y cualesquiera otras que apruebe el $\mathrm{Mi}$ nisterio.

3. El Reglamento de Servicios de las Corporaciones locales desarrolla las normas anteriores. Aunque la disposición transitoria 11 del texto refundido de la Ley de. Régimen local dice que "hasta que no se publiquen los reglamentos para la apli- 
cación de la presente Ley, seguirán provisionalmente, en cuanto no se opongan a ella, las disposiciones reglamentarias actualmente en vigor», es el hecho que, quizá por la gran proximidad en el tiempo entre el Reglamento de Servicios y el texto refundido de la Ley de Régimen local, no puede decirse haya divergiencias entre ellos en este punto, por lo que el Reglamento está plenamente en vigor (o al menos ha estado hasta la implantación del novísimo sistema. Volveremos sobre este punto; pero, desde luego, creo que en esta materia continúan vigentes tanto el texto refundido de la Ley de Régimen local como el Reglamento de Servicios).

I. a) El Regilamento reitera que la cooperación provincial se establece para costear preferentemente cuantos servicios señalan los artículos 102 y 103 de 1 a Ley como obligaciones municipales mínimas, pudiendo también ucomprender aquélla (la cooperación), la redacción de planes de urbanización, construcción de caminos municipales o rurales, y otras obras y servicios de la competencia municipal” (art. 162), todo ello en Municipios menores de 20.000 habitantes (art. 161).

b) Los órganos que intervienen en la ejecución del sistema y sus respectivas atribuciones son:

$\left.a^{\prime}\right)$ Una Comisión informativa, para preparación y estudio de los asuntos (art. 157).

b’) La Comisión provincial de Servicios técnicos, cuya misión es fiscalizar, adoptar las medidas para que la Diputación cumpla su misión, dictaminar planes y aportar iniciativas e informar expedientes (art. 158).

c’) El Ministerio de la Gobernación, a quien compete resolver los recursos, aprobar los planes y señalar la cantidad anual que cada Diputación debe destinar a la cooperación (art. 159), cantidad que tiene el carácter de mínima y no disminuíble (art. 176).

c) El plan de cooperación, que será bienal, contendrá, entre otros datos, Memoria sobre el estado de las obras y servicios en cada Municipio, así como de su situación económica, presu- 
puesto de cada obra, programa escalonado de realizaciones y medios previstos.

d) "La aportación de los Ayuntamientos para establecer servicios por el sistema de cooperación, se fijará en cada caso con arregilo a su capacidad económican (art. 170).

II. Como vemos, la intentio legis de estos textos era instituir un sistema de ayuda a los Ayuntamientos débiles para "la efectividad de los servicios municipales", a costa del erario de las Diputaciones provinciales y Cabildos insulares, de los cuaLes declara el propio Reglamento de Servicios ser ésta una "misión obligatorian (art. 156). El interés del sistema radica en qu:, contrariamente a todo l'o anterior, no se trata de prever ex lege subvenciones o anticipos a cargo de organismos determinados para atenciones determinadas, sino a cargo de un organismo único (la Corporación provincial) y para atender al establecimiento de todos los servicios de la competencia municipal.

No parece aventurado ver en el esquema que, grosso modo, se acaba de establecer de la cooperación provincial a los servicios municipales, un antecedente del sistema subsiguiente de ayuda a las economías municipales, y que está constituído por:

C) La Ley de Reforma tributaria de 26 de diciembre de 1957 Y NORMAS COMPLEMENTARIAS

Dice la exposición de motivos de aquélla, y "como aspecto destacable en relación con los gastos públicos", que "se autoriza la formación de planes provinciales de inversión, que serán ayudados por el Estado, a cuyo efecto se concede un crédito de mil millones de pesetas, al que se incorporan además las partidas que en presupuestos anteriores venían ya atendiendo en varios Departamentos ministeriales inversiones de rango provincial. Con esta medida se reducirá sensiblemente la necesidad de las Corporaciones locales de acudir al crédito, y, lo que es más importante, se conseguirá una descentralización a todas luces conveniente, pudiendo obtenerse una más perfecta utili- 
zación de los fondos en cada Provincia, toda vez que las autoridades locales viven al día sus problemas y pueden apreciar mejor su grado de necesidad y urgencia. Sin embargo, se conserva en un organismo central la facultad de decidir en último término sobre la aplicación de los fondos, ya que también es precisa una visión nacional' en su administración si se quiere lograr la más perfecta coordinación entre el Estado y las. Corporaciones locales".

Como dice García de Enterria (en su breve estudio sobre "Los planes provinciales de obras y servicios", inserto al final de su libro Problemas actuales de régimen local): "No puede ser más significativa esta innovación, si notamos el evidente contraste que en el seno de esta Ley financiera presenta la asignación generosa de mil millones de pesetas para esta atención nueva, frente al criterio de restricción. de gastos públicos, que drásticamente se ha seguido con todas las demás partidas tradicionales". En efecto, el planteamiento de la Ley en este punto es, por lo pronto, ide amplia generosidad. Este es un elogio que, en todo caso, se la debe tributar, sobre todo si se tiene en cuenta que el crédito de mil millones se ve incrementado con las partidas que anteriormente atendían, en los estados de gastos de diversos Ministerios (y de las que ya se ha hablado), inversiones provinciales. Dejemos, no obstante, para más adelante, y en la crítica de la Ley, otros adjetivos-favorables y adversos-. Constatemos simplemente ahora, su evidente generosidad.

1. I. El texto articulado de la Ley de Presupuestos, regula la' "(ayuda" en su artículo 16, que dice:

1. El Gobierno está autorizado para señalar créditos, para obras o servicios provinciales o locales. $Y$ cuyos créditos pueden pertenecer:

a) Al propio Presupuesto general del Estado.

b) A los de los organismos paraestatales.

2. A las Comisiones provinciales de Servicios técnicos puede ser atribuída la administración de los referidos créditos. De dichas Comisiones dice el artículo que comentamos:

a) Funcionarán en Pleno o en Comisión Permanente. 
b) Las preside el Gobernador civil.

c) El Gobierno podrá:

$\left.a^{\prime}\right)$ Fijar sus atribuciones en orden a las actividades que en este artículo se les encomiendan.

b') Ampliar su composición con los Jefes de Servicios centrales en las Provincias, o con los representantes de actividades u organismos locales que considere procedente.

3. ${ }^{\circ}$ Las Comisiones elevarán a la Presidencia propuesta de necesidades de obras y servicios ide la Provincia, y en las que se precise la colaboración del Estado, o de los organismos paraestatalles. Dichas propuestas contendrán:

a) Orden de preferencia entre ellas, a juicio de la Comisión.

b) Aportaciones que la Comisión puede hacer icon cargo a sus recursos propios".

c) Aportaciones de las Corporaciones, Entidades o particulares.

4. ${ }^{\circ}$ La Presidencia deberá :

a) Estudiar las propuestas.

b) Proponer a la Comisión de Asuntos económicos o a la de Sanidad y Asuntos sociales:

$\left.a^{\prime}\right)$ Las obras o servicios que en el año han de ser realizados 0 iniciados.

$\left.b^{\prime}\right) \mathrm{El}$ orden en que deban serlo, teniendo en cuenta:

a') Recursos disponibles.

$b$ ") Aportaciones of recidas.

c") Importancia de la ejecución desde el punto de vista nacional.

$d$ ") Coordinación de los planes provinciales con el plan nacional que habrá de redactarse.

5. La Comisión delegada distribuirá los créditos, por Ministerios y Provincias, comunicándolo a aquéllos.

6. Cada Ministerio procederá a :

a) Asignar a la respectiva Provincia el crédito o parte de él que se le haya atribuido. 
b) Comunicará lo anterior a su propia Sección de Contabilidard, a la Ordenación central de Pagos y a la respectiva Delegación de Hacienda.

7. La Comisión provincial realiza la obra, que en la parte a pagar por el Estado lo será directamente a los acreedores mediante órdenes de la propia Comisión-que se atendrá en todo al capítulo $\mathrm{V}$ de la Ley de Contabilidad-que producirán mandamientos de pago de las Delegaciones de Hacienda.

II. Hasta aquí, un resumen del texto legal. Veamos cómo ha sido acogido. La doctrina ha reaccionado diversamente ante él. Para García de Enterría (lugar citado), que esperaba que "lo que se intentaba, era una auténtica descentralización a favor de las Provincias (en cuanto entes locales)", o, por lo menos, "que al fin se llevaba a l'a práctica la previsión general del apartado último del artículo 243 de la Ley de Régimen local, que prevé un régimen de delegación de funciones estatales a las Provincias, mediante subvención, fórmula de plena actualidad en todos los países"; "nada de eso ha ocurrido en la realidad-añade-. La propia Ley de Presupuestos, all pasar de su preámbulo al texto preceptivo, ha cambiado en esencia el sistema"... "resulta que ya no son las Corporaciones locales las administradoras de estos planes provinciales, sino un organismo de la Addministración idel Estado, Ias Comisiones provinciales de Servicios técnicos, que al efecto se han extraído del ambiente apacible que la Ley de Régimen local las deparaba...", "en definitiva, no se ve por parte alguna la descentralización, y las Corporaciones, no sólo no han de resultar institucionalmente las beneficiarias del sistema, antes bien, su posición parece oscurecerse...).

Resulta un tanto desconcertante que García de Enterria hable así en un libro donde páginas atrás (introducción a su magistral conferencia sobre la Ley del Suelo), ha dicho que ha procurado «abordar los problemas de régimen local más en su sustancia' material de servicios y actuaciones, que en la vestidura formal de la famosa autonomía y de sus abstractos problemas jurídicos, que es el aspecto que nuestro municipalismo viene pre- 
firiendo...". Además, la parte dispositiva no traiciona al preámbulo, si bien hay que reconocer que sólo de una manera remota puede hablarse de descentralización. Lo cierto-y aquí habla la modesta voz de un profesional, mediado su segundo quinquenio de experiencia secretarial-es que, por encima de la famosa autonomía, a quienes en la esfera local perseguimos la eficacia, nos preocupa bien poco; por encima de la famosa autonomia, repito, la Ley de Presupuestos vigente ha puesto una nota altamente esperanzadora en la vida local española; y que las normas que con rapidez no usada en nuestra Administración, la están desenvolviendo, están convirtiendo aquella esperanza en hechos.

Creo que es digno de loa el que los organismos de la Administración salgan de ambientes apacibles, para-sin perder la paz-entrar en ambientes de quehacer. Nadie habrá dudado que las Comisiones provinciales de Servicios técnicos que fueron saludadas como una de las mejores innovaciones de la Ley: de Régimen local, deben tener una actuación más intensa que la que hasta ahora se les encomendaba, y se debe sacar de ellas su ancho margen de posibilidades. Es indudable que sólo ellas pueden fijar un criterio preferencial entre las obras y servicios a acometer en una Provincia. Podría ser discutible el que sean las Comisiones-y no las Corporaciones-quienes administren el dinero asignado, habida cuenta, sobre todo, que estas últimas en muchos casos cooperan con su aportación. Pero el criterio para decidir este punto debe ser el de lá: eficacia y no otro. Ya. veremos que el apartamiento de las Corporaciones cómienza a cesar en la Orden ministerial de 21 de julio de 1958, que admite también la subvención a cobras ejecutadas por las Corporaciones locales".

Parece estar de acuerdo García de Enterría con la atribución a un organismo central de la decisión sobre la distribución de los fondos, decisión que así tiene una visión nacional; sin em bargo, censura el importante papel reservado a la Presidencia, a costa de desnaturalizar organismos creados para más altos fines, como la O. C. y P. E., ya que no deben atribuirse a dicha Presidencia, en su función coordinadora, funciones mate- 
riales de gestión. Al exponer las normas complementarias, será tratado este punto. Pero desde luego creo que deben atribuirse a la Presidencia hasta convertirla, si es preciso en un Ministerio de Economía, cuantas competencias de ámbito nacional-no funciones materiales de gestión, en cuyo aspecto tiene razón la crítica de Enterría-en el campo económico andan hoy desperdigadas.

2. I. El Decreto de 13 de febrero de 1958.

Tiene, respecto a la Ley, el rango de unormas reglamentarias para regular la tramitación" (Preámbulo).

Corroborando lo que muy agudamente ha observado García de Enterría, acerca de que lo que en realidad hacen los artícutos 101 y siguientes de la Ley de Régimen local, es confundir competencia con capacidad, acude a estos artículos para decirnos qué entiende por "obras o servicios de carácter eminentemente local o provincial", enumerando "especialmente" algunos que coinciden casi totalmente con los que el Reg'lamento de Servicios citaba como objeto de la cooperación provincial. El artículo $4 .^{\circ}$ dice quiénes integran el Pleno de la Comisión provincial (todos los Jefes de los Servicios estatales en la Provincia, tres representantes de la Diputación, el Jefe del Servicio provincial de Inspección y Asesoramiento, los Procuradores en Cortes que ostenten la representación de la Provincia y sus Municipios, etcétera), y, "para un plan determinado, aquellas personas cuya colaboración se juzgue conveniente, designadas por el Gobierno Civil, previa consulta a la Presidencia del Gobierno. Será Secretario el de la Diputación, o un funcionario estatal o local designado por la Comisión». Integran la Permanente el Gobernador, el Presidente de la Diputación, el Delegado de Hacienda y el Secretario, "además, podrán incorporarse a ella otros miembros del Pleno hasta un máximo de tres, designados, previa consulta a la Presidencia del Gobierno, por el Gobernador civil, de acuerdo con las características económicas de la Provincia y con las obras o servicios a realizarı. Según el número 5 de este artículo, "a las reuniones puede asistir, cuando la Presidencia del Gobierno lo estime oportuno, un economista de1 Estadon. 
El artículo $6 .^{\circ}$ crea las Comisiones comarcales, con iguales atribuciones que las provinciales respecto a los planes que motivaron su creación.

Los artículos 7 y 8 regulan minuciosamente das propuestas de obra que, precedidas de una memoria, deberán contener los extremos siguientes:

a) Situación y perspectivas económicas provinciales según lo siguiente:

Uno. Nivel de empleo, con expresión para cada sector de la actividad económica de si hay pleno empleo, paro (ćcclico, estacional o permanente) o escasez de mano de obra.

Dos. Aspiraciones económicas de la Provincia' y obras necesarias para conseguirlas.

b) Obras que se proponen. Clasificándolas a’sí :

Uno. No rentables (aquellas cuyo rendimiento es ide evaluación prácticamente imposible, desde un punto de vista económico privado).

Dos. Rentables.

$\mathrm{Y}$ especificando para cada una, coste total e inversión en el ejercicio, volumen y valor de materiales, mano de obra (especificando categoria laboral) y tiempo previsto. En las rentables, además, el valor anual del rendimiento.

c) Forma de gestión más adecuada. Sólo en casos muy uespeciales y justificados", se declarará-y ello se hará expresamente-la excepción de subasta o concurso (art. 14, dos).

d) Forma de financiación, indicando la aportación de la Corporación interesada.

e) Obras y servicios que se prevén en el mismo ejercicio con cargo exclusivo a los fondos de Entidades locales. A cuyo fin (art. 15), el Ministerio de la Gobernación remitirá a la Presidencia, antes del $10^{\circ}$ de febrero de cada año, una relación de aquéllas.

f) Copias de los presupuestos de los entes afectados.

g) Razonamiento de la necesidad y urgencia.

A su vez, según el artículo 12 , los índices a tener en cuenta por la Comisión delegada en la aprobación de los planes son: 
aportaciones del Ente interesado y porcentaje de ellas en relación con su presupuesto ordinario, rentabilidad inmediata, empleo de mano de obra, recursos, y aquellos otros de carácter social que se estimen en cada caso pertinentes.

II. Nos parece que la documentación exigida es excesiva. El peligro de que más de un trámite sea cumplido formulariamente, es claro. Exigencias como Ia de la «copia autorizada del presupuesto", suponen trabajo de envergadura. Por otra parte, los criterios a seguir por la Comisión delegada en la aprobación de los planes, son diversos de los que proponía la Ley a la Presidencia para establecer el orden de inversiones (esta labor ordenadora nuevamente se le encomienda a la Presidencia en el artículo 12 del Decreto y aquellos criterios eran : aportaciones, importancia nacional y de la obra y coordinación con el plan nacional).

Es evidente que la crítica apoyada en la débil representación de las Corporaciones interesadas, es totalmente fundada; contando entre sus representantes al Jefe del Servicio de Inspección, son siete miembros locales entre un total de, por lo menos, veinticinco. Por otra parte, este número de veinticinco es, para un trabajo realmente eficiente, excesivamente alto. Por último, observemos que nada menos que en tres ocasiones es necesario contar con la voluntad de la Presidencia del Gobierno: para ampliar el Pleno, para que un miembro suyo pase a la Permanente y para la asistencia de un economista. Ahora sí que se ha dado/ la razón a Enterría cuando dice que la rdescentralización no se ve por parte alguna". González Pérez, en este punto de la excesiva intervención de la Presidencia en la designación de miembros de la Comisión, se encuentra también en la línea crítica adversa.

Como último elemento de la crítica del Decreto, digamos que con técnica no muy aceptable, a'guno de sus artículos repite/ casi literalmente lo ya establecido por la Ley, defecto en el que insisten las normas posteriores. Digamos también que se utilizan en general con alguna imprecisión, los tecnicismos "local", "municipal" y "provincial".

3. I. La Orden ministerial de 29 de marźo de 1958. 
Ha sido dictada por la Presidencia rpara la aplicación del Decreto de 13 de febreron, a cuyo fin se dictan las siguientes "instrucciones". Sólo expondremos aquí aquella parte de las instrucciones que suponen verdaderas innovaciones, algunas de no pequeña entidad.

Respecto a las obras o servicios que deben ser objeto de los planes, se señalan las siguientes:

a) "Salvo que otra cosa se acuerde por la Comisión delegarda, no se incluirá toda obra objeto ide plan nacional aprobada por el Gobierno, tales como los de construcciones escolares, grandes polígonos de urbanismo, colonización de grandes zonas y concentración parcelarian.

b) La Comisión delegada correspondiente, al aprobar los planes, determinará aquellas obras que, aun habiendo de satisfacerse con créditos cuya administración se realice por las Comisiones provinciales, deban ser ejecutadas por los órganos del Departamento ministerial a que correspondan, en razón de exigencias técnicas o a la participación económica del Estado u organismo paraestatal. A este efecto, informarán a la Comisión delegada los respectivos Ministerios (art. 6. ${ }^{\circ}$, uno). En este caso, las funciones de la Comisión provincial Permanente sỏlo afectan a la administración de los créditos (art. $3 .^{\circ}$ ).

c) Se prohiben las ayudas de cualquier tipo, para obras locales o provinciales, sin que estén incluídas en los planes respectivos, salvo acuerdo de la Comisión delegada.

d) Cualquier ayuda para las referidas obras, consistente en anticipo o préstamo, será tramitada por conducto de la Comisión provincial de Servicios técnicos, y administrada por la misma.

Respecto a la integración de las Comisiones, el articulo $2 .^{\circ}$ contiene diferentes previsiones para los casos en que los organismos representados abarquen más de una Provincia, o estén desdoblados, o se nombre Secretario a funcionario que no sea el de la Diputación, o se amplíe el número de vocales. El artículo 4. ${ }^{\circ}$, dice: "En Alava y Navarra, la Comisión provincial de Servicios técnicos será sustituida por el órgano colegiado que, a propuesta de las respectivas Diputaciones, y previo informe 
de la Dirección General de Administración Local, designe la Presidencia del Gobierno».

El artículo $5 .^{\circ}$ atribuye, para Ceuta y Melilla, a las Juntas coordinadoras de los Servicios de Administración, las funciones que el Decreto encomendaba a las Comisiones provinciales de Servicios técnicos, determinándose a continuación quiénes forman la Comisión Permanente en aquellas plazas.

Respecto a la coordinación con la cooperación provincial, el artículo $9 .^{\circ}$ dice que ésta "principalmente atenderá a los fines siguientes": facilitar a los Municipios la ayuda suplementaria para la ejecución de planes nacionales; prestación de servicios municipales, y obras que no hayan sido posible realizar con cargo a los créditos que administren las Comisiones provinciales. $Y$ con relación a aquéllas de estas últimas cuya realización si se lleva a cabo la cooperación provincial, se concretará en asistencia técnica para redactar proyectos y subvenciones o anticipos a las obras, bien cubriendo la aportación municipal, bien contribuyendo a aquéllas.

Por último, y como disposición transitoria, se autoriza a cada Ministerio para ejecutar con arreglo a la legislación anterior y durante el actual ejercicio, las obras ya aprobadas antes de la fecha del Decreto (13 de febrero de 1958).

II. Comentando esta Orden ministerial, Enterría ha dicho de la disposición transitoria citada "que es un reconocimiento del enorme esfuerzo que está costando improvisar el sistema creado por la Ley de Presupuestos..., no dice la Orden si esa facultad de los Ministerios se extenderá también, y en qué cuantía sobre la partida presupuestaria de los mil millones de pesetas; autoriza a que en casos concretos, que no es difícil imaginar que serán la mayoría, puedan los propios Ministerios realizar directamente las obras...; crea un sistema peculiar de Comisiones para Navarra' y Alava, aunque no se vea en qué pueda afectar un problema estrictamente de la Administración del Estado al régimen foral...; trata de regular la materia de cooperación provincial contradiciendo la Ley de Régimen local, para lo que evidentemente carece de rango propio..., todo ello parece jus- 
tificar por sí solo que no se meditó bien el importante paso que - Ia Ley de Presupuestos ha dado...".

Es evidente-y ello comporta por nuestra parte un elogio para los encargados de tan difícil tarea-que la puesta en práctica de la renovadora Ley Fiscal, está costando un gran esfuerzo. No es fácil llevar a cabo reforma tan radical en tan breve plazo de tiempo. Claro que lo que es un elogio para el espíritu de trabajo de los encargados de una acelerada ejecución, podría ser una censura para el espíritu de improvisación de los encargados del planeamiento. No hay tal censura por nuestra parte. La Ley de Presupuestos ha sido un poco en este punto, una quema de las naves. $Y$ ello es un acierto. Aparte de que su elaboración ha llevado varios meses-casi todo el año 1957 -, lo importante era innovar el sistema. $\mathrm{Y}$ así lo ha hecho la Ley de Presupuestos, con un contenido muy genérico, como corresponde a su rango, pero con la suficiente precisión para que la propia Administración quedara embargada en un difícil periplo en pos de la eficacia. Es cierto que a medida que va siendo desarrollada la complicación de trámites, aumenta excesivamente-cosa corregible-, y es cierto también que no puede ya hablarse de descentralización.

j: Examinemos la's críticas concretas al Decreto:

En primer lugar, no parece presumible que los Ministros puedan disponer gastos sobre la partida presupuestaria de mil millones. Dicha partida está incrementada en las cantidades previstas anteriormente en cada Departamento para atenciones provinciales, y parece lógico pensar que es a esas cantidades a las que se refiere la disposición transitoria. En segundo lugar, sólo la naturaleza de la obra debe determinar el que sean los Servicios técnicos de un Ministerio y no los de la Comisión provincial, quien la lleve a cabo (pensemos, por ejemplo, en las traidas de aguas, ejecutadas por las Confederaciones Hidrográficas), aunque, desde luego, debe reconocer que al decir el Decreto en su artículo $6 .^{\circ}$, número 3 in fine, que "la documentación correspondiente (se refiere a las obras ejecutadas por los Servicios técnicos de la Administración central) se remitirá a las Comisiones provinciales de Servicios técnicos para su ulterior tramitación y pagon, 
debe reconocerse, repetimos, que la complicación aumenta. En cuanto a las peculiaridades para Navarra y Alava, compartimos en absoluto la postura de Enterria. Dice González Pérez que sería discutible el que se preste ayuda a unas Provincias que ya cuentan con privilegios fisca'es, pero que hay servicios que en todo caso deben atenderse por el Estado, no obstante cua'esquiera privilegio. Exacto. Lo que ya no me parece justificado es que si los privi'egios no obstan para que la ayuda exista, si obsten para que sea en las mismas condiciones que a las Provincias de régimen común. Por ùltimo, es evidente que una Orden mi-/ nisterial no puede regular de nuevo la cooperación provincial, que ha sido establecida en una norma con rango de ley. Tan sólo un argumento puede inclinarnos a 'a solución opuesta: el entender que el artícuio 16 de la Ley de Presupuestos al autorizar al Gobierno para "fijar las atribuciones de las Comisiones provinciales en orden a las actividades que en este artícu'o se las encomiendan", ha derogado los artículos 255 a 258 de la Ley de Régimen local. Esta interpretación es muy arriesgada. Las actividades que la Ley de Presupuestos encomienda a las Comisiones se limitan a administrar créditos de los presupuestos del Estado o de organismos paraestata'es, y la Diputación no es ni el Estado ni un organismo paraestata:. En realidad, el ataque a la cooperación provincial no nace de los articulos de la Orden ministerial que hablan de ella, sino de los que prohiben toda ayuda no incluida en los p'anes. Aparte des problema juríd:co forma!, creo que es lógica la supeditación de la cooperación a los planes provinciales de obras y servicios, y que debe-con norma de rango adecuado-consagrarse definitivamente este criterio. Mi experiencia en cuanto a la muitip.ic.dad de fuentes de ayuda a los Municipios, es totalmente negativa.

4. La Orden ministerial de 28 de junio de 1958.

I. Cont:ene "normas provisiona'es sobre contratación, intervención y ordenación de los gastos y pago de las obras y servicios que se realicen por as Comisiones frovincia'es y comarcales de Servicios técnicos, cuando se financien total o parcialmente con fondos de: Presupuesto general de! Estado o de los 
organismos autónomos". Los rasgos principales de esta Orden ministerial son :

a) Obras efectuadas por las Comisiones provinciales: Cuando las Comisiones provinciales conozcan la aprobación de un plan, elaborarán el proyecto definitivo comprensivo de todas las condiciones técnicas.

Los Interventores de las Delegaciones de Hacienda (cualquiera que sea la cuantía del gasto), fiscalizarán toda propuesta a cargo del Presupuesto del Estado o de los organismos autónomos. Los Interventores de las Corporaciones fiscalizarán los acuerdos de contribuir. El artícul.o $4 .^{\circ}$ establece un modo de dirimir las divergencias en este punto entre el Interventor provincial y el Presidente de la Comisión provincial, encomendándolo al Interventor general del Estado. Si el informe de éste es desfavorable, se remite el expediente a la Presidencia. y caso de que ésta se conforme con el dictamen de aquél, se entenderá denegada la propuesta, mientras que caso contrario se somete la discrepancia a la Comisión delegada de Asuntos económicos.

El artículo 5..$^{\circ}$ establece que si los pagos afectan a más de un presupuesto, deberán ser aprobados wexpresamente» por la Comisión ministerial dé.egada de Asuntos económicos; debiendo acudirse a la Presidencia del Gobierno cuando haga falta Decreto u Orden para exceptuar una obra o adquisición de las normas genera'es de contratación; y debiendo asistir el Abogado de: Estado y el Interventor de Hacienda: a la Junta de subasta o concurso.

El artícu'o 7. contiene normas acerca del ingreso de sus aportaciones por las Corporaciones (lo que se hará en la sección de acreedores de la cuenta de Tesoreria de la Delegación de $\mathrm{Ha}$ cienda), aportaciones que, previo acuerdo de la Comisión provincial, serán devueltas caso de no ser invertidas. Recibidas las certificaciones de obras o servicios (en las que se detallará la parte a abonar por e! Estado y la que corresponda a los demás partícipes), los Delegados de Hacienda expedirán un mandamiento de pago con cargo al Estado, y otro con cargo a la cuenta en la 
que, previamente, los partícipes habrán hecho sus ingresos, dando cuenta mensual a la Dirección General del Tesoro.

b) Obras ejecutadas por la Administración central. Se sujetarán a lo previsto para los expedientes normales de los respectivos Ministerios, enviando las certificaciones de obras a la Comisión provincial correspondiente, para que la Comisión Permanente de la misma acuerde su pago.

II. Parece, por consiguiente, en el caso $b$ ), que la intervención de la Comisión provincial de Servicios técnicos es nula, ya que se les encomienda un trámite nimio, cual es el del acuerdo de pago; luego, diga lo que diga el artículo $3 .^{\circ}$ de la Orden de 29 de marzo, no puede decirse que administren nada. Por otra parte, en la regulación del apartado a), la complicación de procedimiento parece excesiva. En efecto, cuando la Comisión provincial ha aprobado el plan, to ha elevado a la Presidencia, ésta lo ha enviado a la Comisión delegada correspondiente; ésta lo ha aprobado y ha sido devuelto a la Presidencia, debe la Comisión provincial elaborar el proyecto definitivo, aprobar la Comisión Permanente las propuestas de gastos que se deriven de él, y estas propuestas ser fiscalizadas por los Interventores provinciales, pudiendo en este trámite naufragar todo lo hecho. Además, al aprobar el plan la Comisión ministerial delegada, debe aprobar los pagos que afecten a más de un presupuesto, etc.

5. La Orden de 21 de julio de 1958.

I. Por ella "se amplía el texto de la Orden de 28 de junio de 1.958 ", con un apartado más dedicado a "obras ejecutadas por las Corporaciones locales".

Cuando por "circunstancias especiales" convenga encargar a una Corporación alguna obra, la Comisión provincial lo propondrá razonadamente a la Presidencia, la que resolverá previo acuerdo con el Ministerio de Hacienda.

La Corporación obrará según las condiciones mínimas que le fije la Comisión provincial, y ateniéndose a la legislación específica local. Por intermedio de la Comisión provincial, se comunicará a la Dirección General del Tesoro importe de la adjudicación, plazos de ejecución e importe de la aportación estatal; 
de este modo dicha Dirección General hará las consignaciones necesarias a la Delegación de Hacienda respectiva.

Las certificaciones de obra se elevarán a la Comisión de Servicios técnicos, y aprobadas por la Permanente se enviarán con orden de pago de su Presidente a la Delegación de Hacienda, donde una vez intervenida, el Delegado producirá mandamiento de pago "en concepto de subvención a la Corporación local».

II. El olvido en que se ha tenido a las Corporaciones, en cuanto a la intervención en la elaboración de planes, y del que se ha quejado la doctrina, comienza a ser rectificado. Se introduce en el sistema', por primera vez, el Reglamento de Contratación de las Corporaciones locales, en contraposición a la repetida remisión que hasta ahora se había hecho al capítulo $5 .^{\circ} \mathrm{de}$ la Ley de Contabilidad. Por primera vez dejan las Comisiones provinciales su ininterrumpido papel de administradoras, en cuanto a la aportación municipal; resultando ilógico que esta aportación continúe sometida para los casos de los apartados a) y $b$ ), a las complicadas comprobaciones que en ellos se establecen. Resulta también falto de lógica y de sistema el que unas veces se aplique la normativa estatal para contratación. y otras la local. Por último, parece que la resolución de la Presidencia debía ser previa consulta con los Ministerios técnicos y no con el de Hacienda.

6. Intentemos ahora, a la vista de la Ley de Presupuestos, del Decreto y de las tres Ordenes ministeriales expuestas, construir el itinerario de toda petición de obras y servicios municipales y provinnciales, acogido al sistema instituido por dicha Ley.

En primer lugar, hay que advertir que, salvo acuerdo de la Comisión delegada de Asuntos económicos, no podrá acogerse al sistema obras comprendidas en el plan nacional aprobardo por el Gobierno, tales como escuelas, grandes planes de cơnización, etc. (Orden de 29 de marzo, art. 1. ${ }^{\circ}, 2$ ).

En segundo lugar, la no inclusión en el plan comporta ia consecuencia de que en ningún caso se concederán subvenciones ni ayudas de cualquier tipo para realizar obras de carácter local o provincial. La vis atractiva del nuevo sistema es ab- 
soiuta: obra o servicio que no costee integramente la Corporación, obra o servicio que ha de sujetarse al sistema.

Consignadas estas dos advertencias, distingamos un doble cauce: aquél por el que discurre la concesión de créditos, y aquél por el que discurre la petición de ayuda y posterior concesión de ésta.

a) En cuanto a.l primer punto, el Ministerio de Hacienda comienza por consignar para estas atenciones mil millones de pesetas en el Presupuesto ordinario de gastos del Estado. A continuación "comunica a los Departamentos y organismos interesados, los créditos que una vez aprobado el presupuesto, deberán incluir en una relación que, antes del 15 de enero de cada año, a su vez los Departamentos interesados enviarán al de Hacienda', y cuya relación comprende los créditos que debiendo emplearse en la ejecución de obras y servicios de los planes provinciales, han de ser administrados por las Comisiones provinciales de Servicios técnicos (art. 10, Decreto).

En un plazo de quince dias, a contar desde la recepción de las anteriores propuestas, el Ministerio de Hacienda las informa y las envía a la Presidencia, para someterlas a la aprobación de la Comisión delegada de Asuntos económicos (Decreto, artículo 11).

b) Independientemente de lo anterior, la Presidencia deberá tener antes de $1 .^{\circ}$ de febrero de cada año, una relación que el Ministerio de la Gobernación le enviará, de las obras y servicios que se proyectan realizar durante el ejercicio con cargo exclusivamente a los fondos de los Ayuntamientos y Diputaciones, o por aquéllos con subvención de éstas, y de cuantas subvenciones consignen unos y otras para obras, servicios u organismos de cualquier alcance (Decreto, art. 15, 2). Además de ello, la Presidencia podrá solicitar de ‘a Dirección General de Administración Local informe sobre la relación de obras y servicios de que se acaba de hablar (Orden de 31 de marzo, art. 10).

c) El trámite de las peticiones de ayuda es el siguiente:

$\left.a^{\prime}\right)$ Con antelación suficiente para que en $10^{\circ}$ de septiembre puedan las Comisiones provinciales haberlas despachadio, las 
Corporaciones solicitarán de aquéllas sean inc'uidas ‘as obras o servicios en la propuesta que el Pleno de la Comisión, según el artículo 6, Decreto, debe elevar al Gobierno. Nada obsta a que la Comisión la inciuya sin petición previa. Dicha propuesta debe ir precedida de una Memoria valorada en la que se caicularán los costes con la mayor aproximación (art. 7, 2, Decreto). A las propuestas se acompañarán los extremos previstos en el artículo 8 , Decreto, y que ya se han relacionado (sobre la economia local, obras a realizar, formas de gestión y financiación, obras a realizar exclusivamente con fondos locales, y presupuestos de estas Entidades).

$\left.b^{\prime}\right)$ Recibidas las propuestas en la Presidencia, por los organismos competentes de la misma se estudiarán; se propondrá el orden de prioridad, Decreto, artículo 12, uno (para este orden, el artículo $\mathbf{1 6}$ de la Ley de Presupuestos dice que se tendrá en cuenta: recursos disponibles, aportaciones, importancia desde el punto de vista nacional y coordinación con el plan nacional).

c') Estudiadas por la Presidencia, pasan las propuestas a la Comisión delegada correspondiente, al que deberá :

$a^{\prime \prime)}$ Determinar las obras que deben ser ejecutadas por los órganos de la Administración central (art. 6. ${ }^{\circ}, 2$, Orden 29 marzo).

$b^{\prime \prime)}$ Aprobar los planes, teniendo en cuenta las aportaciones de las Corporaciones, el porcentaje del' presupuesto de las mismas destinado a las obras, rentabilidad, empleo de mano de obra y recursos (art. 12, 2, Decreto).

c') Determinar si procede la excepción de subasta o concurso (art. 14, 3, Decreto), ateniéndose al artículo 57 de la Ley de Contabilidad (art. 7. ${ }^{\circ}, 2$, Orden 29 marzo).

d') Simultáneamente al envío a las Comisiones, la Presidencia enviará a los Ministerios competentes relación valorada de las obras, para que éstos informen cuáles no deben ser ejecutadas por las Comisiones provinciales (art. 6., 1 , Orden 31 marzo).

$\left.e^{\prime}\right)$ Los acuerdos de la Comisión delegada se notificarán 
a la Sección de Contabilidad de los Ministerios interesados, a la Ordenación central de Pagos y a la Delegación de Hacienda respectiva (art. 14, 1, Decreto), aparte, como es lógico, de comunicarlos a la Comisión provincial interesada.

$\left.f^{\prime}\right)$ Recibido el plan ya aprobado por la Comisión provincial, ésta, a través de su Comisión Permanente $-\mathrm{y}$ en el caso de que corresponda a ella la ejecución-, procederá a elaborar el proyecto definitivo comprensivo de todas las condiciones técnicas (art. 2..$^{\circ}$ Orden 28 junio), y convocará subasta o concurso con arreglo a los trámites del capítulo V de la Ley de Contabilidad (art. 14, 2, Decreto y art. 5. Orden 28 junio), habida cuenta de que la aprobación del plan implica la declaración de utilidad pública, de acuerdo con el artículo 10 de la Ley de Expropiación forzosa (art. 14, 3, Decreto) y observando lo dispuesto en el artículo $5 .^{\circ} d$ ) de la Orden de 28 de junio, que dice que a las subastas o concursos asistirá el Interventor y el Abogado del Estado de la Delegación de Hacienda.

g') Las propuestas de gastos serán aprobadas por la Comisión provincial de Servicios técnicos'y fiscalizadas por los Interventores (el de Hacienda en cuanto a desembolsos estatales, y los de los demás organismos en cuanto a sus propias aportaciones) (art. $3 .^{\circ}$, Orden 28 junio).

h') Contratada una obra o servicio, las Comisiones provinciales comunicarán a la Dirección General del Tesoro el importe exacto de la adjudicación y plazos en que deberá ejecutarse. Dicha Dirección General comunicará a las Delegaciones de Hacienda la concesión de las consignaciones necesarias para que los pagos puedan efectuarse en las fechas convenientes (art. 6. ${ }^{\circ}$, Orden 28 junio). Las aportaciones de las Corporaciones y organismos paraestatales ingresan en una cuenta de la Dele-. gación de Hacienda. Los pagos a acreedores en la parte a satisfacer por los recursos del Estado, serán abonados directamente mediante órdenes de la Comisión provincial que producirán mandamientos de pago de las Delegaciones (Decreto, artículo 14,1 ; art. $8 .^{\circ}$, Orden 28 junio). I as certificaciones de obra 
detallarán la parte correspondiente a fondos del Estado y la correspondiente a aportaciones, expidiéndose mandamientos separados contra cada clase de fondos (arts. $8 .^{\circ}$ y $8 .^{\circ}$, Orden 28 junio).

i') Para los servicios y obras ejecutados por los Servicios técnicos centrales, los trámites a partir de $f^{\prime}$ ) son sustituidos por la tramitación de expediente normal en el respectivo $\mathrm{Mi}$ nisterio (art. 13, Orden 28 junio), si bien las certificaciones de obra expedidas por aquellos Servicios técnicos se remitirán a la Comisión provincial respectiva, para que ésta acuerde el pago en la forma prevista en el apartado A) de la Orden de 28 de junio.

j) Para obras ejecutadas por las Corporaciones locales, parece lógico suponer que la propia Corporación, al solicitar la inclusión de una obra en el plan, pida el que se le encargue de su ejecución. Si la Comisión provincial patrocina esta petición, la eleva a la Presidencia, quien resuelve acerca de la misma, de acuerdo con el Ministerio de Hacienda. Caso de que se acepte la petición, se comunica a la Comisión provincial, y ésta lo hace a l'a Corporación, la cual deberá:

a') Sujetarse a la legislación local en cuanto a la contratación.

b") Comunicar a la Comisión provincial: importe de la adjudicación, plazos de ejecución y cuantía de la aportación estatal.

c") Expedir certificación de la parte de obra ejecutada, haciendo constar la cuantía que corresponde al Estado.

La Comisión provincial, deberá:

a') Comunicar los datos que la facilite la Corporación en cuanto a importe de la adjudicación, etc., a la Dirección General del Tesoro.

b") Hacer, si lo cree oportuno, las comprobaciones convenientes respecto a obra ejecutada.

c") Aprobar las certificaciones de obra.

d") Expedir orden de pago junto con cada certificación, para que sea cumplimentada por el De'egado de Hacienda. 
El Delegado de Hacienda, intervenida la documentación, expedirá mandamiento de pago, y sólo en ouantía correspondiente a la parte de obra ya ejecutada.

\section{D) ConClusiọ́n}

La Ley de presupuestos y normas que la complementan, merecen en conjunto una crítica altamente elogiosa. La complicación de trámite en algunos puntos, ya señalados, es excesiva $y$, técnicamente, es claro que no puede hablarse de descentralización, ya que, la única norma que lleva hacia la periferia antiguas competencias centrales, es la intervención a cargo de los Interventores provinciales, cualquiera que sea el volumen de la cantidad intervenida; y esto no constituye en realidad descentralización, sino desconcentración. Por otra parte, la Comisión provincial debe ser reducida, pues el número de sus componentes es excesivo; y además, las Corporaciones afectadas están insuficientemente representadas. Se echa de menos también una norma que consagre la posibilidad de que la decisión de la Comisión relativa a la inclusión de aquélla en un plan, pueda ser revisada.

Pero lo que importa es el resultado. $Y$ el autor de estas líneas puede decir que ha perdido mucho tiempo y alguna ilusión, tras la no lograda financiación de diversas obras y servicios, al amparo del sistema anterior a la Ley de Régimen local, tan prolífico en normas como infecundo en rea'izaciones. Valga por todos, un hecho: En ei Ayuntamiento en que trabajo, se tardó - al parecer, pues este dato es anterior a mi llegada- varios años en reunir materiales para completar el expediente de traída de aguas, dando tiempo a que diversas elevaciones de precios hicieran inservible el proyecto primitivo; concluso el expediente en el año 1954, fué e'evado a los organismos competentes, sin que hasta fin de 1957 pudiera saberse de él nada efectivo. Acogido el proyecto al nuevo sistema, la convocatoria de là subasta no se hará esperar mucho tiempo. Y esto es lo que cuenta: la eficacia. ¿ No vale la pena sacrificar la famosa autonomia, si este sacrificio aplaca la sed de un pueb.o? 